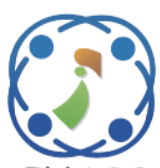

\title{
Optimal Allocation of Distributed Generation with Reconfiguration by Genetic Algorithm Using Both Newton Raphson and Gauss Seidel Methods for Power Losses Minimizing
}

\author{
Lubna A. Alnabi ${ }^{1 *}$ \\ Abbas K. Dhaher ${ }^{2}$ \\ Mohammed B. Essa ${ }^{3}$ \\ ${ }^{I}$ Computer Techniques Engineering, Almustafa University College, Iraq \\ ${ }^{2}$ Ministry of Oil, Iraqi Drilling Company, Iraq \\ ${ }^{3}$ Electrical Techniques Department, Al Sowaira Technical Institute, Middle Technical University, Iraq \\ * Corresponding author's E-mail: lubna.cet@almustafauniversity.edu.iq
}

\begin{abstract}
The power loss in electrical networks is considered unavoidable, because of its inherent resistance, for effective and economical operation; network loss should be reduced to maximum extent. There are two goals for this study, the first one is extracting the optimal size and location of distribution generators (DG) and the optimal reconfiguration with the aim of decreasing power loss and enhance voltage profile, while the second objective is to prove the success of the methods of Newton Raphson (NR) and guess sidle(GS) in the study and analysis of radial distribution networks. In order to reduce power loss, the genetic algorithm (GA) is used to address the network distribution problem. Software package MATPOWER-7 and MATLAB are utilized to simulate a 33-bus testing system for achieving four cases of various Distribution generator (DG) numbers. A comparison with another previous studies done and the conclusion indicated a positive impact on the efficiency of the system, this work support loss reduction and voltage improvement with the lowest Distribution generator (DG) size and prove that the increase of Distribution generator (DG) number not always can give better result though system cost increase, maintenance, along with the units' distance for gas supplying increases. There are 4 cases with distinctive Distribution generator (DG) number applied in this paper and a compassion is done of power losses and voltage profile with references where case 4 show better result with voltage profile 0.96 and power losses 59.09. As load flow method the Gauss-Seidel (GS) method used because it is a simple iterative method for solving $\mathrm{n}$ number of load flow equations by using iterative method. Where partial derivatives not require. And a Newton-Raphson (NR) method used where it is based on Taylor's series and partial derivatives. The Newton-Raphson (NR) method advantages are less number of iterations needs to reach convergence, takes less computer time when computation cost is less and the convergence is definite. Also it is more accurate, and is insensitive to factors like slack bus selection, regulating transformers. and the number of iterations required in this method is almost independent of the system size. Genetic algorithm (GA) has a good ability to making a global search and explore the search space using their different kind of crossover. Also you can combine it with local search method to increase the exploitation search of the Genetic algorithm. In this paper the introduction part introduced where it is the general part of the paper then the research method proposed in section 3 with details then a Genetic algorithm proposed finally the result with conclusions are proposed.
\end{abstract}

Keywords: Reconfiguration, Newton raphson, Guess sidle, Distribution generator.

\section{Introduction}

The systems of electric power distribution include groups related to inter-connected radial circuits, also they have several constraints such as voltage drop within limit, all load served, radial configuration, coordinated operation regarding the over current protective devices, and so on, each one of the distribution system's feeders has distinctive combination regarding industrial and commercial loads' type, with day-to-day load variations. Because of the system, loads uncertainty on various feeders that is changing often the operation as well as the 
control of distribution systems was further complicated especially when there is high load density. Furthermore, power loss in the distribution networks will not be minimum with regard to a fixed network configuration for all instances of different load values [1].

Considerable power loss is caused by the distribution system network, often in an order between 10 and $13 \%$ regarding the output that was generated. Poor and ineffectiveness network's voltage regulation caused via the high distribution loss. For enhancing and increasing the effectiveness of system's voltage regulation, network was reconfigured adequately, also locally added DGs as solar photovoltaic (PV), wind turbine, diesel generator, and so on, might decrease the loss, boost the system capacity and enhance the voltage profile. Yet, allotment of distribution generator (DG) or network reconfiguration might not be random since it could lead to ineffective performances and unplanned network operation. Also the radial arrangements related to network feeders should be kept following reconfiguration. Placement and size of distribution generator (DG) should be enhanced in a way that power loss has been reduced satisfying system constraints on bus voltage, line capacity and power balance [2].

The reconfiguration of network was reached via opening typically closed sectionalizing switches and after that close typically opened switches. Modifying the topology of the network will impact the operating point of the power distribution network, thus the distribution companies attempt on finding the optimum topology, thus the operating point which is related to distribution network was optimal taking into account satisfying the technical constraints (for instance, radial structure, feeding all loads, current and voltage limits). Elimination overloads on the components of network is another reason of distribution reconfiguration [3].

The network reconfiguration can be defined as a process used to alter the open/closed status regarding sectionalizing as well as loop switches, therefore adapt novel topological structures for decreasing the power loss and enhance the reliability of a system.

The process of network reconfiguration was sometimes examined within two instances: (1) scheduled reconfiguration because of seasonal variations and large load changes; (2) reconfiguration for the power service restorations. The latter was approximately real time optimization, whereas the former might be planned prior to application. Also, the main aim of reconfiguration was reducing the economic loss, that is going to take a switch operation and average time to the restoration under consideration. With regard to distribution system operation, the uncertainties have been considered to be unavoidable because of the environmental factors and sequential effects existing in distribution network, such uncertainties might be embodied as variability as well as incertitude in the electrical parameters and equipment, like load fluctuations and fault rate of generators [4].

In this paper Newton Raphson method and guess sidle used for radial distribution networks, the GaussSeidel method has the advantages of small memory requirements, relative insensitivity to initial voltage estimates, and programming simplicity. The GaussSeidel approach is simpler compared to NewtonRaphson technique, yet it has better convergence properties although it is faster than Guess Sidle method. Genetic algorithms used as optimization method for distribution networks to minimize the network losses, where genetic algorithms advantages are: optimizes with the discrete or continuous variables, no derivative information needed, a wide cost surface sampling where the search is done also can jump out of a local minimum, a large number of variables can be deal with, supplies a list of optimal variables, not only single solution [5], where no optimal network distribution increases the losses so these techniques used to solve that problem.

\section{Literature survey}

In 2019 Jafar, Siahbalaee, Gevork B. Gharehpetian and Neda Rezanejad, have suggested "Re-configuration and DG sizing and placement using improved shuffled frog leaping algorithm".

All constraints were achieved with the use of an improved shuffled frog leaping algorithm (ISFLA) in the discussed paper regarding distributed generation (DG) and reconfiguration methodology, for achieving switching number operation minimization, power loss minimization, and deviation of bus voltage minimization. The approach was described and tested on IEEE test distribution systems with 69 and 33 buses. The ISFLA performance is compared to that of the refined particle swarm optimization (PSO), genetic algorithm (GA), harmony search algorithm (HSA), differential evolutionary (DE), and standard shuffled frog leaping algorithm (SFLA). The voltage bus in the primary distribution network, as well as total power loss, could be greatly decreased, as demonstrated by simulation findings. In various instances, the distribution generator (DG) placement and simultaneous reconfiguration approach is preferable with reduced losses and minimum voltage, as shown in the conclusion, even though improved shuffled frog leaping algorithm (ISFLA) 
outperforms harmony search algorithm (HAS), shuffled frog leaping algorithm (SFLA), particle swarm optimization (PSO) and differential evolutionary (DE) in terms of convergence speed and accuracy, along with the number of iterations convergences. A comparison is done with prior studies which showed best performance of the presented method [6].

In 2019, Salim Ur Rehman, Suliman Khan, Hashmat Khan and Anees Ur Rehman, suggested "Optimal Placement of Distributed Generation in Power System for Power System Loss Reduction Using ETAP" it is study related to distributed generation (DG) to power grid, in which distributed generation (DG) units non-optimal locations might result in the increase in the power losses. As a result, an optimum approach was used in this work to determine the ideal size and allocation of distributed generation (DG) on an electric power system while reducing power loss. The findings of a Newton Raphson load flow analysis performed on ten bus systems with the use of ETAP software reveal that active power losses decreased from $3302.2 \mathrm{KW}$ to $400.7 \mathrm{KW}$ following installing a $5 \mathrm{MW}$ [7].

In 2019, Slawomir KOZIEL, Alberto LANDEROS, and Mohamed F. ABDEL-FATTAH, suggested "Distribution network reconfiguration using feasibility-preserving evolutionary optimization" A modified evolutionary algorithm was used to a power distribution network reconfiguration (DNR) in this article, in which the algorithm uses recombination operators to keep the viability of solutions for the network's radial structure while drastically shrinking the search space. The optimization procedure was after that used to increase outcomes repeatability and reduce overall computational complexity. The optimization technique takes into account the voltage profile and the system's power losses, which are both aggregated into a scalar cost function [8].

In 2020, Krishan Kumar, Arjun Tyagi, Bhavnesh Kumar and M. A. Ansari, suggested "An efficient load flow solution for distribution system with addition of distributed generation using improved harmony search algorithms" This power flow distribution is of high importance. Various power flow approaches for distributing power flow were suggested. In the case when dispersed generations have been modelled as PQ nodes in the system of the distribution, the implicit Z-bus gauss-seidel (GS) approach is viable, yet when dispersed generations are modelled as solar photovoltaic (PV) nodes, it causes variance difficulties. A tiny variation in the fulfillment related to bus-type switching logic causes a convergence characteristic in a Newton-like approach. Despite the fact that the backward/forward (BW/FW) approach is effective [9].

In 2021, Lubna A. Alnabi, Mohammed B. Essa, and Abbas K. Dhaher suggested "Distribution power loss minimization via optimal sizing and placement of shunt capacitor and distributed generator with network reconfiguration" As the population grows, so do the demands for electrical energy; such increase in load results in increased voltage drop and power loss. This research focuses on an approach for reducing power losses and improving voltage profiles. The first proposed approach, binary particle swarm optimization (BPSO), is used to solve the problem of network distribution power loss minimization. This paper uses a shunt capacitor (SC) with network reconfiguration for showing the enhancement of network distribution efficiency depending on the optimal position and sizing of distribution generation (DG) units. Also, MATLAB and software package MATPOWER7 are applied for simulating a 33-bus and 69-bus test system with 3 load situations and varied numbers of shunt capacitor (SC) and distributed generation (DG). Compared to prior researches, the results demonstrated a positive influence on system efficiency. This study found that increasing the DG and capacitor doesn't always yield the best results, despite higher system costs, maintenance, and unit distance for gas delivery [10].

In this paper Newton Raphson and Guess Sidle methods used for radial distribution network and reconfiguration is done with optimal location of distributed generation (DG) by using genetic algorithm for power loss minimization problem and voltage profile improved where the Gauss-Seidel method is simple method but Newton-Raphson reported to have better convergence characteristics although it is faster than Guess Sidle method so both methods used and the results is compared. As optimal case Genetic Algorithm used for optimal solution. where a population of points generates at each iteration, new population can be an optimal solution.

Like most intelligent optimization algorithms, the shuffled frog leaping algorithm drawback is to fall into local optimization. And for binary particle swarm optimization the major disadvantage of it, is the difficulty in choosing parameters for the backpropagation that can ensure efficient network training.

So this paper proposed the genetic algorithm as an optima case to avoid this problem to make the algorithm jump out of the local optimum and obtain 
better optimization results to some extent.

As a comparison with the first survey proposed in this section reference [6] the power losses reduced to $62.34 \mathrm{KW}$ by using improved shuffled frog leaping algorithm (ISFLA) and reduced to $63.57 \mathrm{KW}$ by using particle swarm optimization (PSO) where for the best case of this paper the power losses reduced to $59.09 \mathrm{KW}$ using genetic algorithm (GA).

\section{Research method}

Load flow can be defined as one of the significant tools utilized via power engineers for planning and determining the best operations for power systems and exchanging the power between the utility companies. The presented study applies two numerical techniques: Gauss-Seidel and Newton Raphson for power flow analysis solution. The main aim of the present work is deciding the optimum reconfiguration as well as DGs allocation in a radial distribution network with the use of two load flow techniques Guess Sidle (GS) and Newton-Raphson (NR) for proving the efficiency of the two approaches of load flow. Simulation was conducted utilizing MATLAB for test case IEEE 33-Bus system [11, 12]. this work applies one of the artificial intelligent (AI) types for determining the optimal distributed generation (DG) location and size as well as network reconfiguration. There were many approaches used for determining value of switches, size and location of distributed generation (DG). Also, unsuitable determination regarding such parameters is going to lead the solution to trap in local optimum, that isn't the best solution. Due to the fact that the combination regarding such method was difficult to solve and complex, therefore, Guess Sidle (GA) was chosen because of robustness. A few instances under population based were: firefly algorithm (FA), artificial bee colony (ABC), binary particle swarm optimization (BPSO), particle swarm optimization (PSO), genetic algorithm (GA), and ant colony system (ACS) [13]. More details on Guess Sidle (GA) are provided in reference [14-17].

\subsection{Gauss siedel (Gs) load flow technique}

This is considered as one of the iterative methods utilized to calculate the power flow analysis, such technique has been termed after two german mathematicians (C. F. Gauss and P. L. von Seidel). Also, it has been referred to as successive displacement technique or liebmann technique. Guess Sidle (GS) is an algorithm which is used for solving a set of nonlinear algebraic equations. Here, a solution vector was expected and an equation is utilized for obtaining the revised value related to specific variable. Also, a solution vector was updated immediately in terms of the variable. After that, the process was repeated for every variable and thus complete one iteration. Also, the iterative procedure was after that repeated until the solution vector converge within the prescribed accuracy. Furthermore, convergence was somewhat sensitive to assumed starting values. The benefits of this approach were its simplicity, reduced computation time for each iteration and not much computer memory requirement. Yet, the drawbacks were the large number of iterations and slow convergence rate. Load flow calculation by Gauss-Seidel method began with the assumed slack bus voltage (typically $V 1=$ $1 \angle 0^{0}$ p.u.), the remaining bus voltages $(n-1)$ were identified via iterative process in the following equations $[18,19]$.

$$
P_{i}=\sum_{j=0}^{n}\left|V_{i}\right|\left|V_{j}\right|\left|Y_{i j}\right| \cos \left(\Theta_{i j}-\delta_{i}+\delta_{j}\right)
$$

Where $P_{i}$ is the real power injected into $i^{\text {th }}$ bus, and $V_{i}$ is the $i^{\text {th }}$ bus voltage, and $V_{j}$ is the $j^{\text {th }}$ bus voltage, and $Y_{i j}$ is the admittance of line between $i^{t h}$ and $j^{\text {th }}$ bus, and $\Theta_{i j}$ is the angle of $Y_{i j}$ element of $Y_{b u s}$ and $\delta_{i}$ is voltage angle of $i^{t h}$ bus and $\delta_{j}$ is the voltage angle of $j^{\text {th }}$ bus.

$$
Q_{i}=-\sum_{j=0}^{n}\left|V_{i}\right|\left|V_{j}\right|\left|Y_{i j}\right| \sin \left(\Theta_{i j}-\delta_{i}+\delta_{j}\right)
$$

where $Q_{i}$ is the reactive power injected into $i^{\text {th }}$ bus Eq. $(1,2)$ were referred to as static load flow equations.

$$
I_{i}=\frac{\left(P_{i}-j Q_{i}\right)}{V_{i}^{*}}
$$

Where $I_{i}$ is the bus current at $i^{\text {th }}$ bus.

$$
V_{i}=\frac{\mathbf{1}}{Y_{i i}}\left(I_{i}-\sum_{\substack{j=1 \\ j \neq i}}^{n} Y_{i j} V_{j}\right) \quad \mathrm{i}=2,3,4 \ldots \mathrm{n}(4)
$$

Where $Y_{i i}$ is the Self admittance of line connected to $i^{\text {th }}$ bus.

For $(k+1)^{t h}$ iteration, the voltage equation becomes

$$
\begin{aligned}
& V_{i}^{(k+1)}=\frac{1}{Y_{i i}}\left(\frac{\left(P_{i}-j Q_{i}\right)}{\left(V_{i}^{k}\right)^{*}}-\sum_{j=1}^{i-1} Y_{i J} V_{j}^{k+1}-\right. \\
& \left.\sum_{j=i+1}^{n} Y_{i J} V_{j}^{k}\right)
\end{aligned}
$$




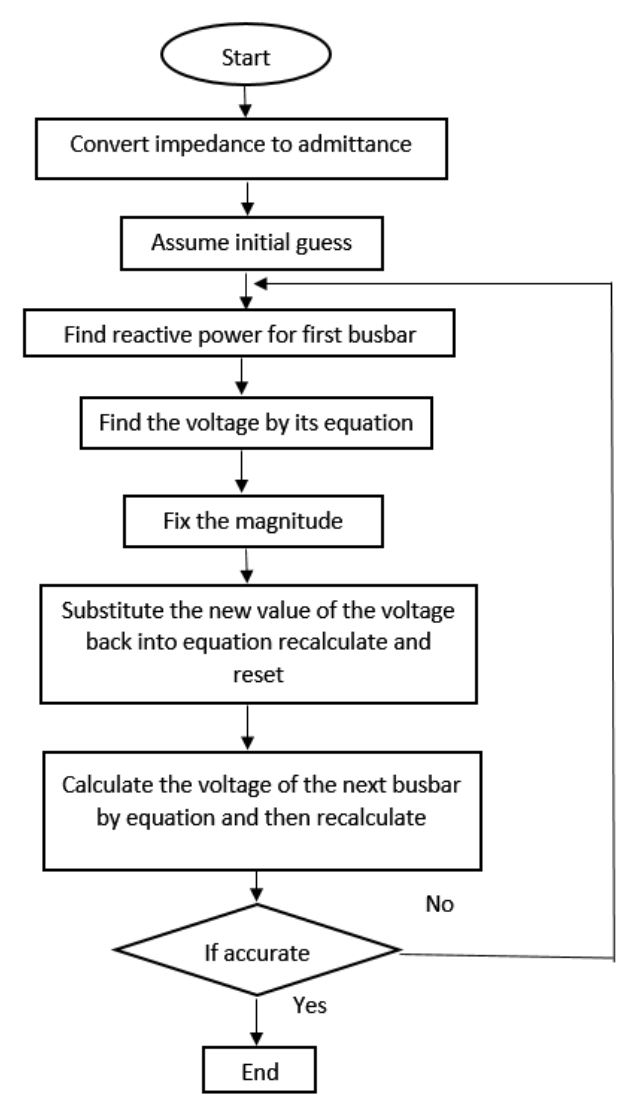

Figure. 1 Flow chart of Gauss-Seidel method [20]

\subsection{Newton Raphson (NR) load flow technique}

Newton Raphson (NR) was termed after Joseph Raphson and Isaac Newton. The origin and formulation of Newton Raphson (NR) approach is dated back to 1960 's. [21] It is considered as one of the iterative methods approximating a set of the simultaneous nonlinear Taylor series expansion, and terms were limited to approximation [22] Also, the Jacobian matrix provides linearized relation between small variations in the magnitude of the voltage $\Delta V$ and its angle $\Delta \delta$ with minor alterations in active and reactive power $\Delta P$ and $\Delta Q$.

$$
\begin{aligned}
& {\left[\begin{array}{l}
\Delta P \\
\Delta Q
\end{array}\right]=[J]\left[\begin{array}{l}
\Delta \delta \\
\Delta V
\end{array}\right]} \\
& \text { Here }[J]=\left[\begin{array}{ll}
J 1 & J 2 \\
J 3 & J 4
\end{array}\right]
\end{aligned}
$$

The partial differentials matrix is referred to as Jacobian matrix $[\mathrm{J}]$. Also, the jacobian elements were evaluated via differentiating the active power and reactive power Eq. $(1,2)$ and substitution of evaluated phase angle and voltage magnitude values. jacobian matrix details are provided in reference [23]. The terms $\Delta Q_{i}^{r}$ and $\Delta P_{i}^{r}$ were the difference between calculated and scheduled valued, referred to as power residuals or mismatch vector, provided via.

$$
\begin{aligned}
& P_{i}(\text { scheduled })-P_{\boldsymbol{i}}^{r} \text { calculated }=\Delta P_{\boldsymbol{i}}^{r} \\
& Q_{i}(\text { scheduled })-Q_{\boldsymbol{i}}^{r} \text { calculated }=\Delta Q_{i}^{r}
\end{aligned}
$$

Computation of $P_{\text {calculated }}$ and $\mathrm{Q}_{\text {calculated }}$ :

The reactive and real powers might be calculated from load flow equations as follows:

$$
\begin{aligned}
& P_{i}=G_{i i}\left|V_{i}^{2}\right|+\sum_{j=0}^{n-1}\left|V_{i}\right|\left|V_{j}\right|\left(G_{i j} \cos \Theta_{i j}+\right. \\
& \left.B_{i j} \sin \theta_{i j}\right)
\end{aligned}
$$

Where $G$ is the conductance.

$$
\begin{aligned}
& Q_{i}=B_{i i}\left|V_{i}^{2}\right|+\sum_{j=0}^{n-1}\left|V_{i}\right|\left|V_{j}\right|\left(G_{i j} \sin \theta_{i j}-\right. \\
& \left.B_{i j} \cos \theta_{j}\right)
\end{aligned}
$$

Where B is the inductive susceptance

$$
\begin{gathered}
|V|^{(r+1)}=|V|^{r}+|\Delta V|^{r} \\
\delta(r+1)=\delta r+\Delta \delta r
\end{gathered}
$$

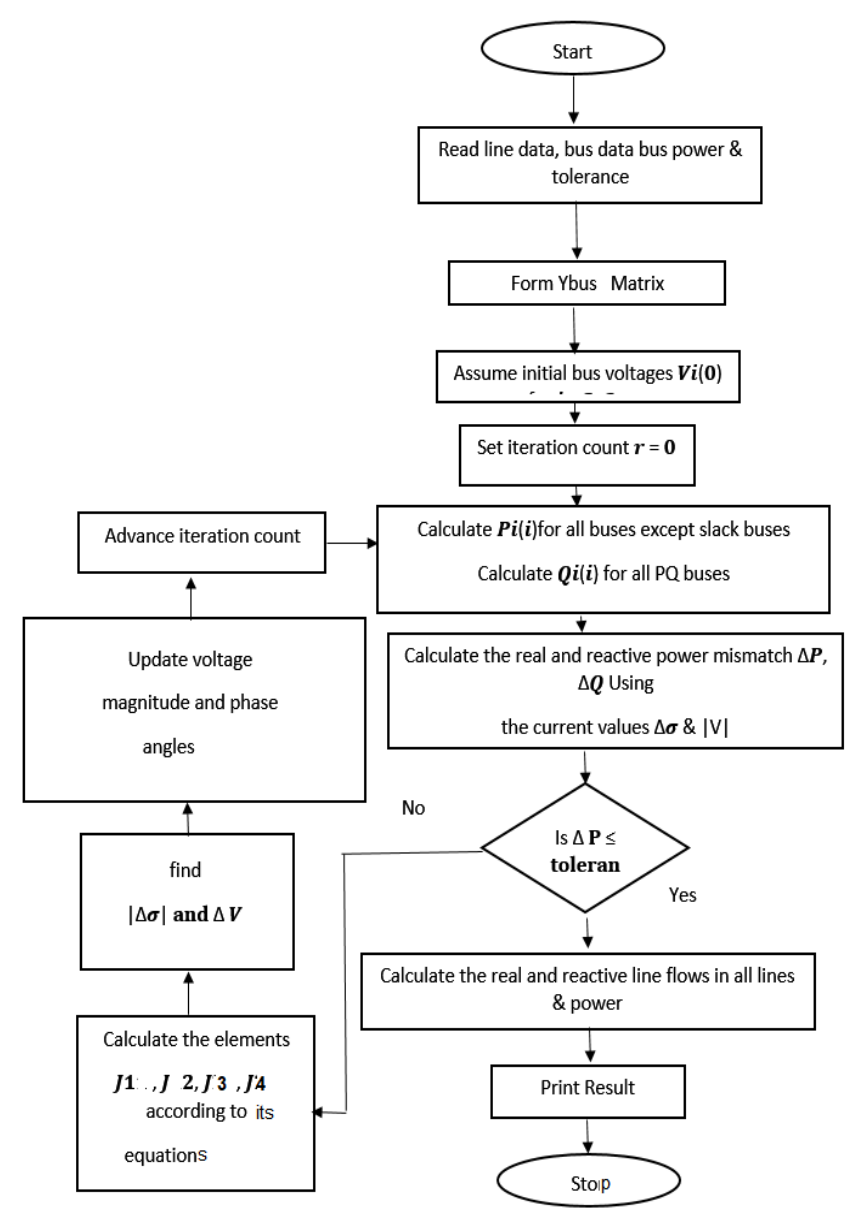

Figure. 2 Flow chart of Newton Raphson method [24] 
Where $r$ the number of iterations.

Flow chart of Newton Raphson method is shown in Fig. 2.

\subsection{Distribution generator}

Distribution generator (DG) was simply modelled as constant real power $(\mathrm{P})$ and reactive power $(\mathrm{Q})$ power source of generation in this study. $\mathrm{P} \_\mathrm{DG}$ and Q_ distribution generator (DG) output of distribution generator (DG) are the characterized distribution generator (DG) model values, in which $P_{-} D G$ is the real power generated by distribution generator (DG) and Q_DG is the reactive power generated by distribution generator (DG). The distribution generators DGs of the fuel-cell kind have been reported to be modeled as a negative PQ-load model. The following load at bus - i with a DG unit will be updated:

$$
P_{\text {load } . i}=P_{\text {load. } i}-P_{D G . i}
$$

Where $P_{\text {load.i } i}$ is the real power consumed at bus $\mathrm{i}$, and $P_{D G . i}$ real power generated by DG injected to bus i.

$$
Q_{\text {load.i }}=Q_{\text {load.i }}-Q_{D G . i}
$$

Where $Q_{\text {load.i }}$ is the reactive power consumed at bus i, and $Q_{D G . i}$ reactive power generated by $D G$ injected to bus $\mathrm{i}$

Throughout the process of the optimization action, following constraints has to be fulfilled with:

System should be radial

$V_{\text {min }} \leq V_{i} \leq V_{\text {max }}$

$/ I_{i} / \leq I_{i .(\max )}$

$$
\begin{gathered}
P_{D G i \min } \leq P_{D G i} \leq P_{D G i \max } \\
Q_{D G i \min } \leq Q_{D G i} \leq Q_{D G i \max }
\end{gathered}
$$

In the presented study, we considered $V_{\max } 1.05$ p.u and $V_{\min } 0.90$ p.u, respectively as maximal and minimal acceptable voltage ranges for network nodes [25].

\subsection{Network reconfiguration}

Fig. 3 show the base configurations with regard to 33 bus systems with dotted lines which normally represent the open tie switches. Also, the nodes (or buses) were numbered in circles. The initial step is applying the algorithm for the optimum reconfiguration, all tie switches and sectionalizing of network were closed. The procedure is creating some loops in network indicated as Loop 5 and Loop 1 in diagrams. Then, any of the switches (sectionalizing or tie) in the loop any one of the network's nodes (buses). Genetic algorithm (GA) is performing many iterations for coming up with switch numbers, opening of which reduces power losses. It has to be indicated that such allocation and operation of DG were simultaneous.

Furthermore, the genetic algorithm (GA) output solutions were the proposed switches for opening along with optimal location and size of distribution generator (DG) which reduces the loss in the network [1].

Network reconfiguration constrains:

1. No load point can be left out of service

2. Radial network structure has to be retained.

\subsection{Objective function}

The goal of objective is to construct the reconfiguration with DGs as radial operating

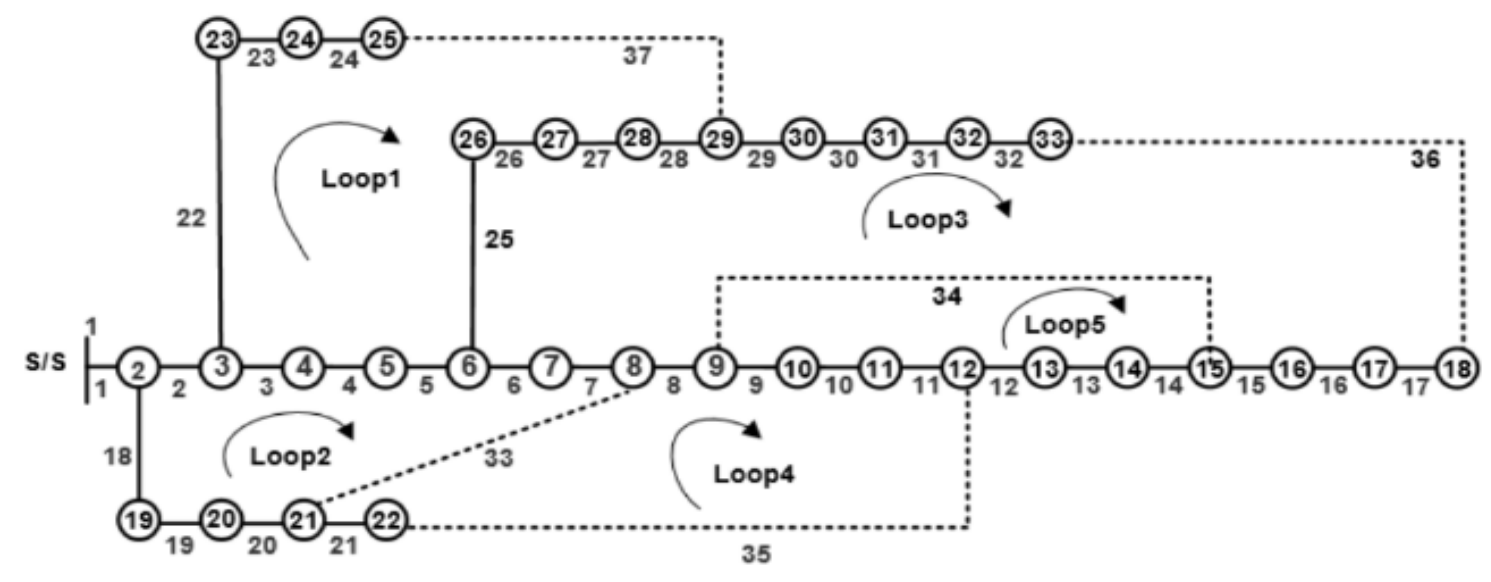

Figure. 3 System model: IEEE 33-bus radial distribution system [1] 
structure so that system power loss minimizes when satisfy the operating constraints. The assume objective function is as shown:

$$
\begin{aligned}
& \text { Minimum } P_{\text {LOSS }}^{T}=\sum_{i=0}^{n-1} P_{\text {LOSS }}(i, i+1) \\
& P_{\text {LOSS }}(i, i+1)=R_{i, i+1} \frac{\left.\left.\left(P_{i}^{2}\right)+Q_{i}^{2}\right)\right)}{\left|V_{i}\right|^{2}}
\end{aligned}
$$

Where, $P_{\text {LOSS }}^{T}$ is total power loss of distribution system, which it is the summation of all power losses of branches.

$P_{\text {LOSS }}$ is power loss of branch between bus (i) and bus (i+1).

$\mathrm{n}$ : number of buses of test system.

The objective function in Eq. (21) is functioned to below operating equality and inequality limitations, where the equations of power flow as shown:

$$
P_{S S}+P_{D G}^{T}=P_{L O S S}^{T}+P_{D}^{T}
$$

Where,

$P_{S S}:$ total power feeding sub-station

$P_{D G}^{T}$ : total power feeding DG units

$P_{L O S S}^{T}$ : total power loss in distribution system

$P_{D}^{T}$ : total power demand of distribution load values

\section{Genetic algorithm}

Genetic algorithm used as optimization for improving issues. Genetic algorithm parallel flavor made it robust for optimizing and proper for nonlinear problems solving of power systems. The parameters of genetic algorithm codes commonly as binary form of finite-length string, simulation is done with rich database of points where searches done from population and objective function used without derivate, so less data depending and use probabilistic transition rules [26].

As optimal case genetic algorithm used for optimal solution. where a population of points generates at each iteration, new population can be an optimal solution. the next population by computations selected that involve random choices but for standard algorithm. Usually a single point generates at an iteration and the sequence of points provides an optimal solution where the next point in sequence selects by a deterministic computation [5].

The main operators of the genetic algorithms are reproduction, crossover, and mutation.

1. Reproduction: in this process copies done of individual strings corresponding to $\mathrm{OF}$ values of its and are combined for the formation of the offspring.

2. OF represents the final arbiter of stringcreature's life or death. Fitter off-springs are retained and play a role in the generation of offsprings of the next generation.

3. Cross-over process to choose individuals named parents that will be contribution to the population of next generation.

4. Mutation done with random changes of individual parents to made children. [27]:

Pseudocode for the genetic algorithm is as follow

"Initialize the time $\mathrm{t}=0$

Initialize the population size "m"

Probability of Mutation "Pm", probability of recombination "Pc"

Number of chromosomes "nc"

Allowable limits for each chromosome, "Pmax (nc), Pmin (nc)".

Generation of initial population $\mathrm{B} 0=(\mathrm{b} 1.0, \mathrm{~b} 2.0, \mathrm{bm}$, $0)$

"Generation Loop (time)"

While stop condition is not satisfied:

"Proportional selection"

For $\mathrm{i}=1$ to $\mathrm{m}$

$\mathrm{x}=\operatorname{random}(0,1)$

$\mathrm{k}=1$

While $\mathrm{k}<\mathrm{m}$ and $\mathrm{x}<\sum \mathrm{kj}=1 \mathrm{f}(\mathrm{bj}, \mathrm{t}) / \sum \mathrm{mj}=1 \mathrm{f}(\mathrm{bj}, \mathrm{t})$

$\mathrm{k}=\mathrm{k}+1$

bi, $\mathrm{t}+1=\mathrm{bk}, \mathrm{t}$

End While

End For

"Recombination at one point"

For $\mathrm{i}=1$ to $\mathrm{m}-1$ step 2

If $\operatorname{random}(0,1)<\mathrm{Pc}$, then

$\mathrm{a}=0.5$

$\Delta=\max [\mathrm{bi}, \mathrm{t}(\mathrm{k}), \mathrm{bi}+1, \mathrm{t}(\mathrm{k})]-\min [\mathrm{bi}, \mathrm{t}(\mathrm{k}), \mathrm{bi}+1, \mathrm{t}$

(k)]

bi $+1, \mathrm{t}(\mathrm{k})=\operatorname{random}\{\min [\mathrm{bi}, \mathrm{t}(\mathrm{k}), \mathrm{bi}+1, \mathrm{t}(\mathrm{k})]-\mathrm{a} \Delta$, $\max [\mathrm{bi}, \mathrm{t}(\mathrm{k}), \mathrm{bi}+1, \mathrm{t}(\mathrm{k})]+\mathrm{a} \Delta\}$

$\mathrm{bi}+1, \mathrm{t}+1(\mathrm{k})=\operatorname{random}\{\min [\mathrm{bi}, \mathrm{t}(\mathrm{k}), \mathrm{bi}+1, \mathrm{t}(\mathrm{k})]-\mathrm{a}$

$\Delta, \max [\mathrm{bi}, \mathrm{t}(\mathrm{k}), \mathrm{bi}+1, \mathrm{t}(\mathrm{k})]+\mathrm{a} \Delta\}$

End If

End For

"Mutation operator"

For $\mathrm{i}=1$ to $\mathrm{m}$

If random $(0.1)<\mathrm{Pm}$ then

$\mathrm{k}=\operatorname{random}(0.1) * \mathrm{nc}$

$\mathrm{bi}+1(\mathrm{k})=\operatorname{random}\{\operatorname{Pmax}(\mathrm{k}), \operatorname{Pmin}(\mathrm{k})\}$

End If 
End For

Check stopping criteria

End While".

\section{Results}

There are 4 cases in the 33-bus IEEE standard are explored in this study, which is assessing the authority regarding the presented method to enhance voltage profile and decrease power loss. As shown in Fig. 1, the recommended algorithm was used on IEEE 33-bus radial distribution test system, which includes 32 lines and 5 tie - lines from (33-37). The test system supplied a total of $3715 \mathrm{KW}$ active loads and 2300 KVAR reactive loads with a $12.66 \mathrm{kV}$ system voltage under normal loading conditions. [28]

\subsection{Cases study}

As indicated in tables 1 and 2, the system test is carried out as well as compared to a few studies. In terms of voltage profile and power loss, the results showed an enhancement. Table 2 shows the suggested standard system for IEEE 33-bus with various numbers of distribution generator (DG):

1. Case 1: The approach of network reconfiguration utilized with 1 distribution generator (DG) for the power loss reduction.

2. Case 2: The approach of network reconfiguration utilized with 2 distribution generator (DG) for the power loss reduction.

3. Case 3: The approach of network reconfiguration utilized with 3 distribution generator (DG) for the power loss reduction.

4. Case 4: The approach of network reconfiguration utilized with 4 distribution generator (DG) for the power loss reduction.

Through the results shown in Table 1, it was noticed that genetic algorithm (GA) proved good results with less losses and less DG size compared with the references [1, 6, 12, 28, 30, 31].

In addition, not every increase in the number of distribution generator (DG) has a feasible benefit, because this incrimination will raise the costs of maintenance, operation, fuel transportation, as well as manpower.

As for the results in Table 2, they show the success of the Newton Raphson (NR) and Guess Sidle (GS) method in the radial distribution networks and that the difference between them is very small, reaching a maximum of 0.000912 , and this percentage is good and proves a meeting point for ideal and reliable results.
Table 1. Results comparison with five different references

\begin{tabular}{|c|c|c|c|}
\hline \multirow[b]{2}{*}{ Case } & \multicolumn{2}{|c|}{ Distributed Generator } & \multirow[b]{2}{*}{$\begin{array}{l}\text { Power loss } \\
\quad(\mathrm{kw})\end{array}$} \\
\hline & $\begin{array}{c}\text { no. } \\
\text { Of DG }\end{array}$ & $\begin{array}{l}\text { Total KW } \\
\text { for DGs }\end{array}$ & \\
\hline $\begin{array}{l}\text { Original } \\
\text { System }\end{array}$ & ---- & ---- & 208.5 \\
\hline Ref. [12] & 4 & 1998 & 64.9211 \\
\hline Ref. [29] & 3 & 1788.7 & 64.97 \\
\hline Ref. [30] & 4 & 400 & 108.55 \\
\hline Ref. [1] & 3 & 2500 & 53.15 \\
\hline Ref. [31] & 3 & 1668.4 & 73.05 \\
\hline Ref. [6] & 3 & 2000 & 57.35 \\
\hline \multirow{4}{*}{ Proposed } & 1 & 1710 & 80.55 \\
\hline & 2 & 1800 & 64.4 \\
\hline & 3 & 1800 & 60.92 \\
\hline & 4 & 1800 & 59.1 \\
\hline
\end{tabular}

The Fig. 4, 5, 6, 7, 8 show the comparison of voltage profile between Newton-Raphson and GaussSidle regarding 4 cases with distinctive number of distribution generator (DG), and Fig. 9, 10 showing a comparison of four cases.

\section{Conclusions}

Using the MATPOWER7 software to reduce active power loss in distribution systems has been described in this study, and BPSO was effectively applied. Furthermore, in the event when the reconfiguration is paired with the simultaneous allocation regarding distribution generator (DG)

And SC, the network operation is offered to set the most adequate alternative. From the equivalent articles, the suggested strategy resulted in the least active loss of power $(59.1 \mathrm{Kw})$. The overall installed distribution generator (DG) and shunt capacities (SC) have been fully and efficiently utilized. It also demonstrates that, despite system costs, maintenance, and unit distance for gas providing increments, increasing distribution generator (DG) and capacitor doesn't often produce better results.

Four cases are done with different number of distribution generator (DG) and a voltage profile compared where its approach to $1 \mathrm{pu}$ and the tolerance of power loss between Newton Raphson and Gauss Siedel for best case is 0.0135 .

As a future work another technique for optimization can be uses and compared the result with the result of this paper also another system can be uses to show the effect of genetic algorithm with different system.

\section{Author contributions}

Conceptualization, Lubna A. Alnabi, Mohammed Bahlool Essa and Abbas K. Dhaher; methodology, 
Table 2. Results comparison with four different cases

\begin{tabular}{|c|c|c|c|c|c|c|c|c|c|}
\hline \multirow[b]{2}{*}{ Case } & \multirow[b]{2}{*}{ Open Switches } & \multicolumn{2}{|c|}{$\begin{array}{l}\text { Distributed } \\
\text { Generator }\end{array}$} & \multicolumn{2}{|c|}{$\begin{array}{l}\text { Newton's } \\
\text { method }\end{array}$} & \multicolumn{2}{|c|}{$\begin{array}{c}\text { Gauss-Seidel } \\
\text { method }\end{array}$} & \multicolumn{2}{|c|}{$\begin{array}{c}\text { Tolerance between } \\
\text { N.R and G.S methods }\end{array}$} \\
\hline & & $\begin{array}{c}\text { bus } \\
\text { no }\end{array}$ & $\begin{array}{c}\text { DG } \\
\text { Size } \\
\text { in } \\
\text { MW }\end{array}$ & $\begin{array}{c}\text { Power } \\
\text { loss } \\
(\mathrm{kw})\end{array}$ & $\begin{array}{l}\text { Vmin } \\
(\mathrm{p} . \mathrm{u})\end{array}$ & $\begin{array}{c}\text { Power } \\
\text { loss } \\
(\mathrm{kw})\end{array}$ & $\begin{array}{l}\text { Vmin } \\
(\mathrm{p} . \mathrm{u})\end{array}$ & $\begin{array}{c}\text { Power } \\
\text { loss } \\
\text { Tolerance } \\
(\%)\end{array}$ & $\begin{array}{c}\text { Vmin } \\
\text { Tolerance } \\
\quad(\%)\end{array}$ \\
\hline Original System & $\begin{array}{c}33,34,35,36, \\
37 \\
\end{array}$ & ---- & ---- & 208.46 & 0.9108 & 208.3 & 0.9108 & $0.0912 \%$ & $0.0000 \%$ \\
\hline Case1 & $7,10,14,28,34$ & 30 & 1.71 & 80.554 & 0.9649 & 80.55 & 0.9649 & $0.0000 \%$ & $0.0000 \%$ \\
\hline Case2 & $7,10,14,28,30$ & $\begin{array}{l}33 \\
25 \\
\end{array}$ & $\begin{array}{l}0.84 \\
0.96\end{array}$ & 64.396 & 0.9661 & 64.39 & 0.9661 & $0.0124 \%$ & $0.0000 \%$ \\
\hline Case 3 & $7,10,14,28,30$ & \begin{tabular}{|c|}
8 \\
32 \\
25 \\
\end{tabular} & \begin{tabular}{c|}
0.4 \\
0.62 \\
0.78 \\
\end{tabular} & 60.918 & 0.9636 & 60.91 & 0.9636 & $0.0131 \%$ & $0.0000 \%$ \\
\hline Case4 & $7,10,14,28,30$ & \begin{tabular}{|c|}
14 \\
9 \\
32 \\
25 \\
\end{tabular} & \begin{tabular}{|l|}
0.19 \\
0.29 \\
0.59 \\
0.73 \\
\end{tabular} & 59.093 & 0.9632 & 59.09 & 0.9632 & $0.0135 \%$ & $0.0000 \%$ \\
\hline
\end{tabular}

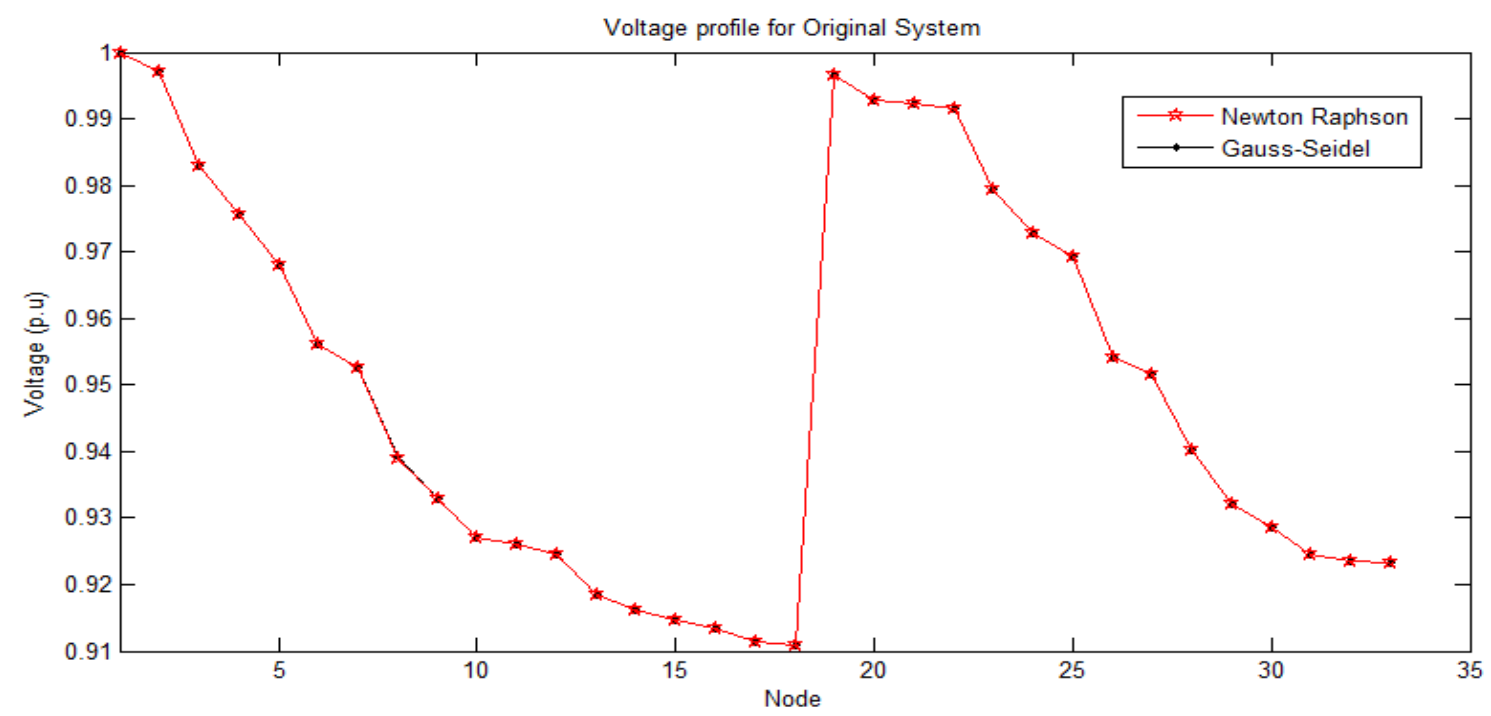

Figure. 4 Voltage profile by (N. R and G. S methods) for original system

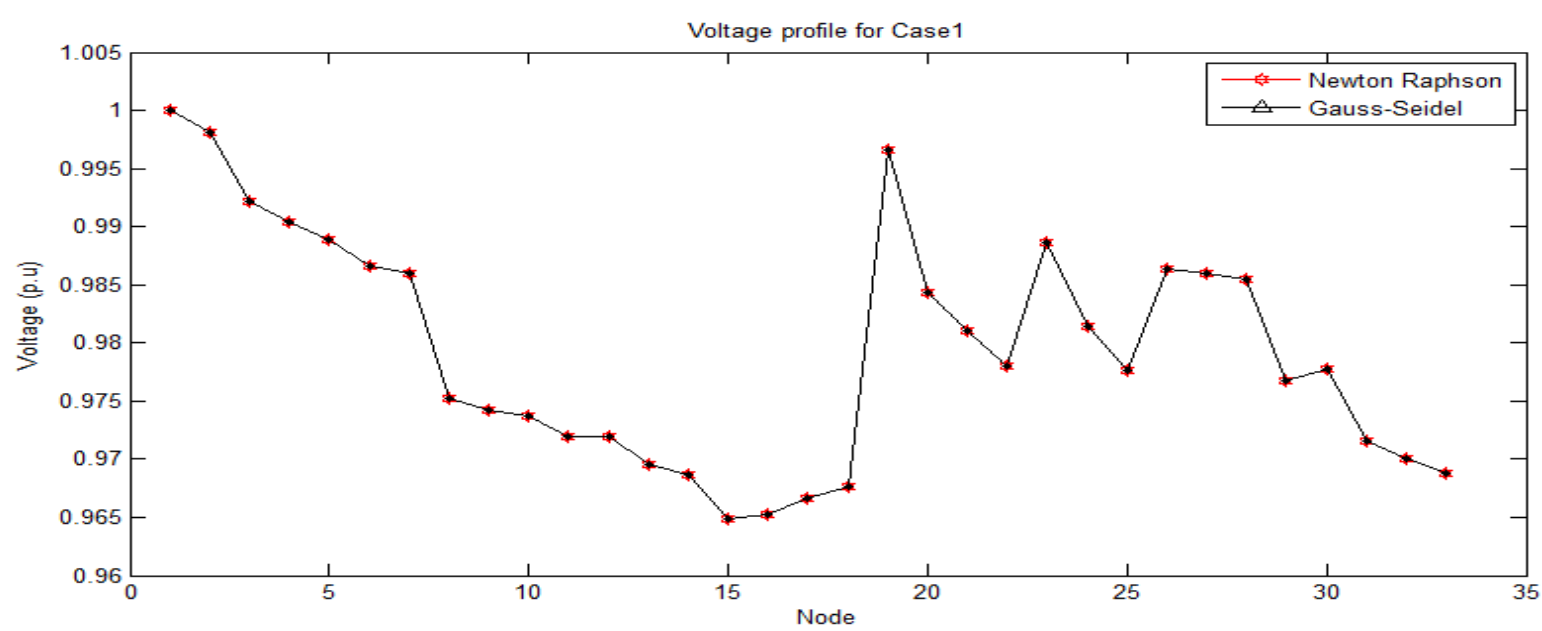

Figure. 5 Voltage profile by (G. S and N. R techniques) for case 1 
Received: August 10, 2021. Revised: November 29, 2021.

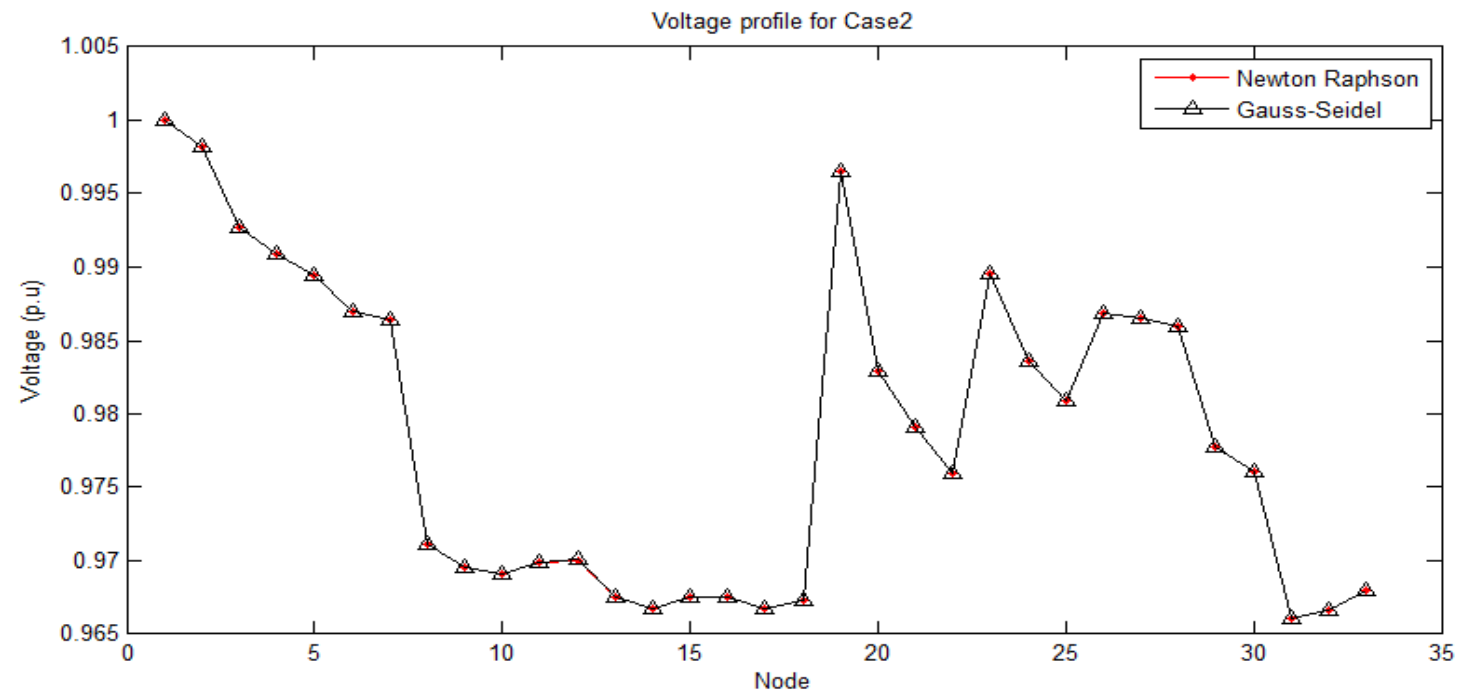

Figure. 6 Voltage profile by (G. S and N. R techniques) for case 2

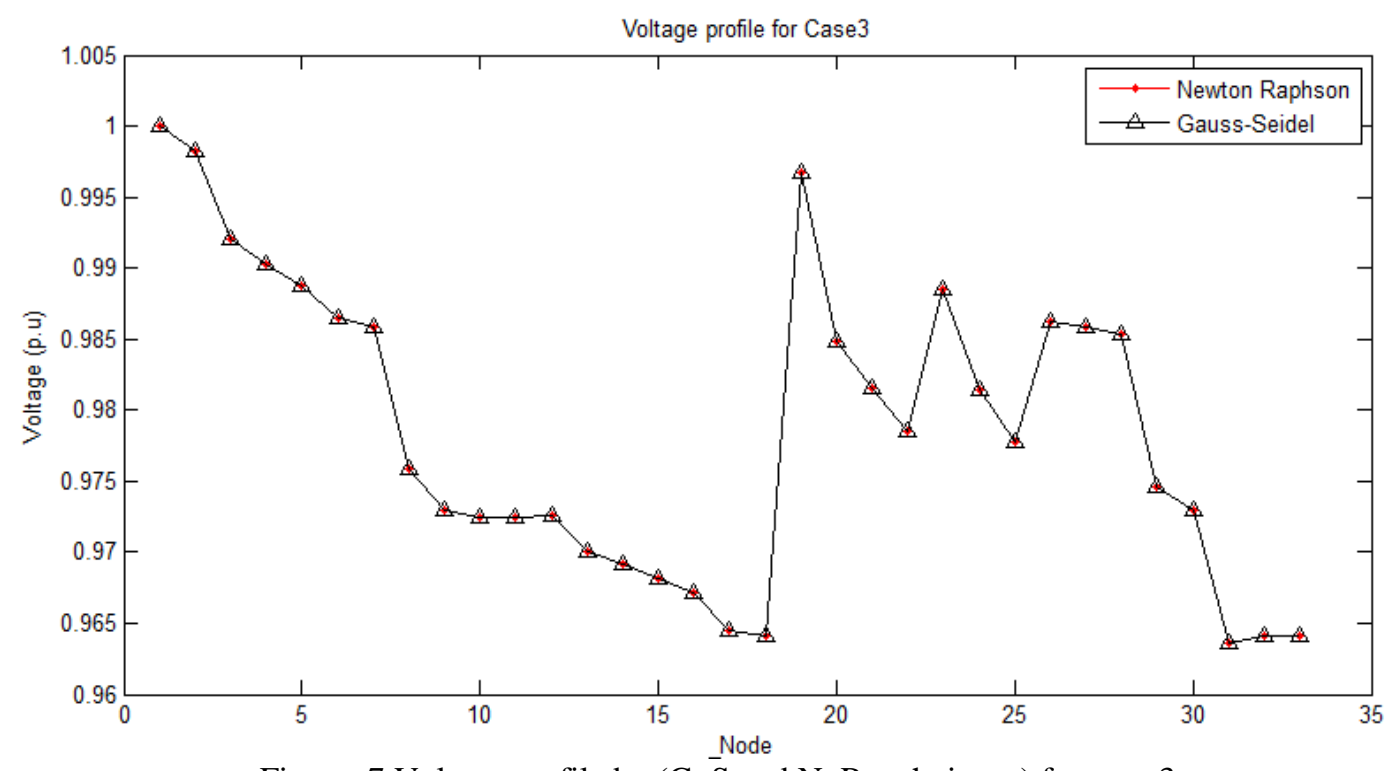

Figure. 7 Voltage profile by (G. $\bar{S}$ and N. R techniques) for case 3

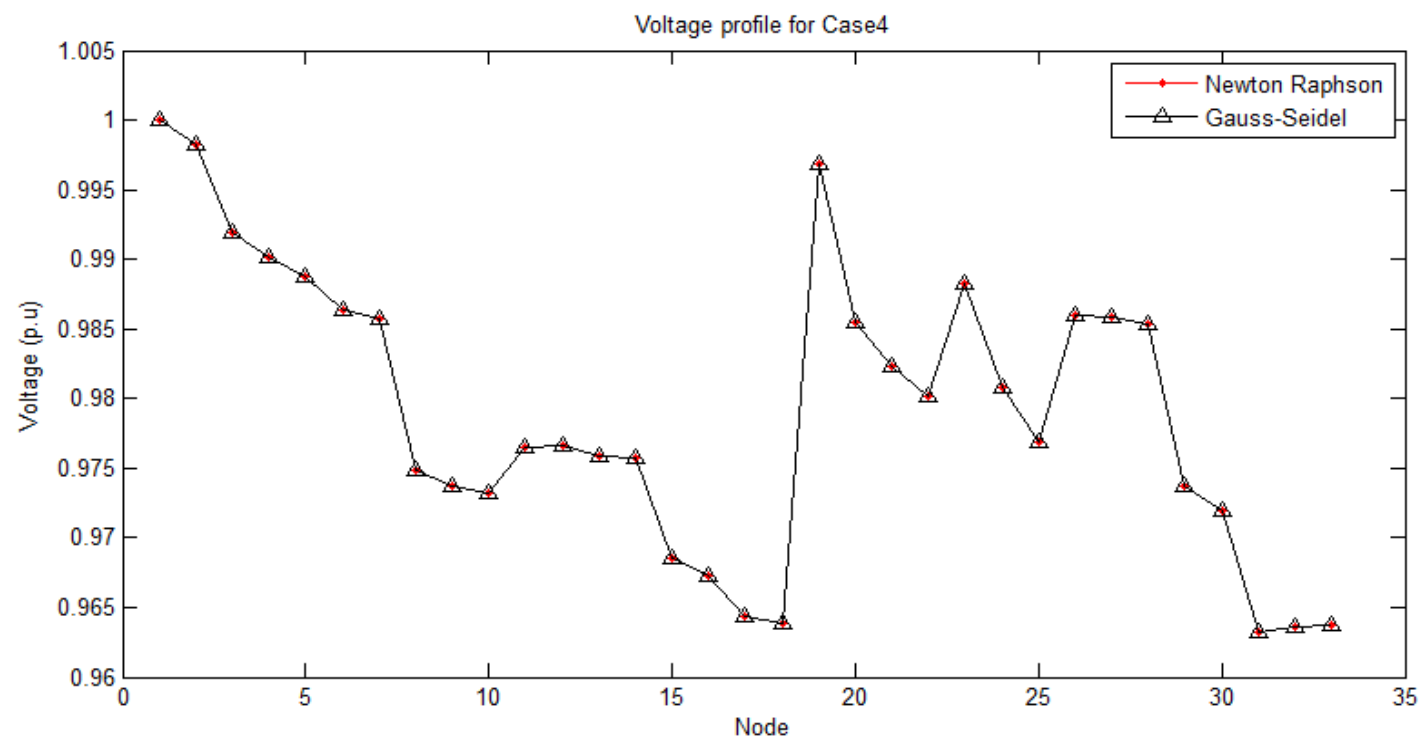

Figure. 8 Voltage profile by (G. S and N. R techniques) for case 4 


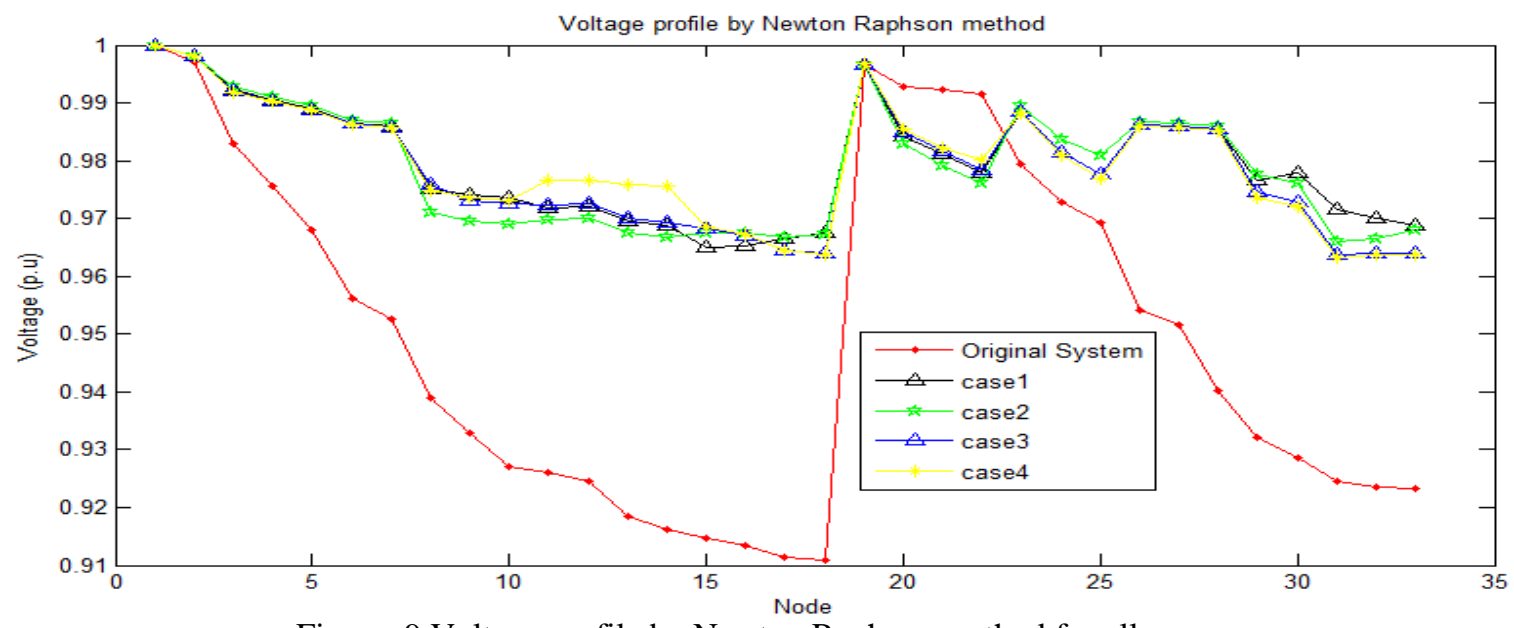

Figure. 9 Voltage profile by Newton Raphson method for all cases

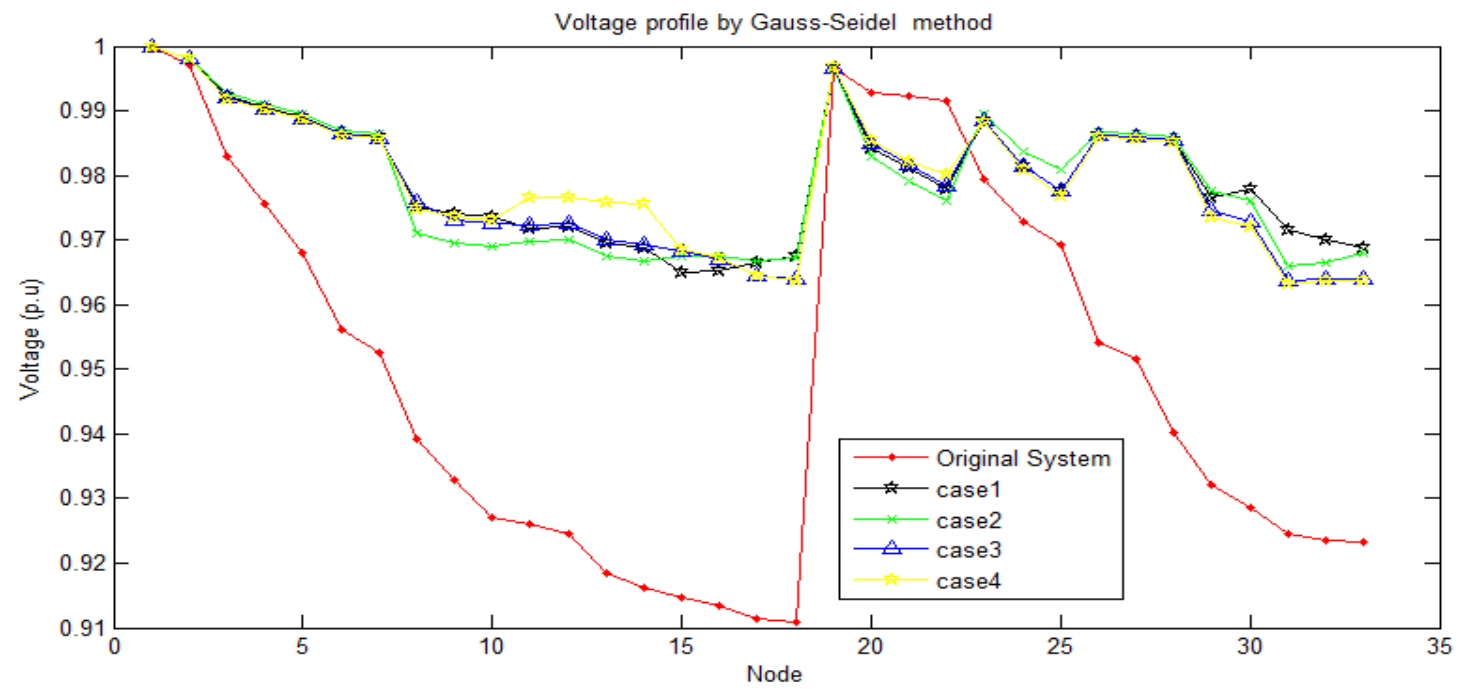

Figure. 10 Voltage profile by Guess Sidle method for all cases

Lubna A. Alnabi, Mohammed Bahlool Essa and Abbas K. Dhaher; software, Lubna A. Alnabi and Mohammed Bahlool Essa; validation, Abbas K. Dhaher; formal analysis, Lubna A. Alnabi, Mohammed Bahlool Essa and Abbas K. Dhaher; investigation, Abbas K. Dhaher; resources, Mohammed Bahlool Essa; data curation, Lubna A. Alnabi; writing-original draft preparation, Mohammed Bahlool Essa; writing-review and editing, Abbas K. Dhaher; visualization, Lubna A. Alnabi; supervision, Lubna A. Alnabi; project administration, Lubna A. Alnabi, Mohammed Bahlool Essa and Abbas K. Dhaher; funding acquisition, Lubna A. Alnabi, Mohammed Bahlool Essa and Abbas K. Dhaher.

\section{Conflict of interest} interest.

\section{Acknowledgments}

The authors would like to acknowledge the Electrical Techniques Department, Al Suwaira Technical Institute, Middle Technical University for their encouragement and support.

\section{References}

[1] P. Biswas and R. Mallipeddi "Optimal Reconfiguration and Distributed Generator allocation in Distribution Network using an advanced Adaptive Differential Evolution", In: Proc. of IEEE Symposium Series on Computational Intelligence (SSCI), Vol. 978, No. 6, pp. 1-7, 6/17/2017.

[2] R. Hasanpour, B. Kalesar, and J. noshahr, "Reconfiguration of Smart Distribution Network Considering Variation of Load and Local Renewable Generation", IEEE Industrial and 
Commercial Power Systems Europe (EEEIC / I\&CPS Europe), Vol. 978, No. 11, pp. 1-5, $7 / 17 / 2017$.

[3] K. Liu, W. Sheng, Y. Liu, and X. Meng, "A Network Reconfiguration Method Considering Data Uncertainties in Smart Distribution Networks", Energies, Vol. 10, No. 5, p. 618, 2017.

[4] T. Anantha "Genetic Algorithm based Network Reconfiguration in Distribution Systems with Multiple DGs for Time Varying Loads", ELSEVIER, SMART GRID Technologies, Procedia Technology, Vol. 21, No. 29, pp. 460467, 2015.

[5] A. Adail "Network Reconfiguration for Loss Reduction in Electrical Distribution System Using Genetic Algorithm", Thesis, Electrical Engineering Department Faculty of Engineering - Al-Azhar University, Arab Journal of Nuclear Science and Applications, Vol. 46, No. 1, pp.7887, 2013.

[6] S. Jafar, N. Rezanejad, and G. Gharehpetian. "Reconfiguration and DG sizing and placement using improved shuffled frog leaping algorithm". Electric Power Components and Systems, Vol. 47, No. 16-17, pp. 1475-1488, 2019.

[7] S. Khan, S. Rehman, A. Rehman, and H. Khan, "Optimal Placement of Distributed Generation in Power System for Power System Loss Reduction Using ETAP", International Journal of Engineering and Technologies, ISSN: 2297623X, Vol. 16, pp 7-19, 2019.

[8] A. Landeros, S. Koziel, and M. A. Fattah, "Distribution network reconfiguration using feasibility preserving evolutionary optimization", IEEE Modern Power Systems and Clean Energy, J. Mod. Power Syst. Clean Energy, Vol. 7, No. 3, pp. 589-598, 2019.

[9] A. Tyagi, K. Kumar, M. Ansari, and B. Kumar, "An efficient load flow solution for distribution system with addition of distributed generation using improved harmony search algorithms", Journal of Electrical Systems and Information Technology, Vol. 7, No. 7, pp. 1-16, 2020.

[10] W. Haider, S. Hassan, A. Mehdi, A. Hussain, G. Adjayeng, and C. Kim "Voltage Profile Enhancement and Loss Minimization Using Optimal Placement and Sizing of Distributed Generation in Reconfigured Network", Machines, Vol. 9, No. 1, p. 20, 2021.

[11] A. Parwaiz, V. Kumar, and B. Ansari, "Comparative Analysis of Load Flow Methods on Standard Bus System", International
Research Journal of Engineering and Technology, Vol. 6, No. 4, pp. 775-780, 2019.

[12] O. Afolabi, W. Ali, P. Cofie, and J. Fuller, "Analysis of the Load Flow Problem in Power System Planning Studies", Energy and Power Engineering, Vol. 7, No. 10, pp. 509-523.

[13] S. Juma, "Optimal Radial Distribution Network Reconfiguration Using Modified Shark Smell Optimization", MSc. Thesis, Pan African University Institute for Basic Sciences Technology and Innovation, No. 4, pp. 1-85, 2018.

[14] M. kabirifa, A. shoaei, M. moallem, "distribution system reconfiguration using heuristic method and enhanced genetic algorithm with fuzzy sets objectives", In: Proc. of IEEE, Iranian Conference on Electrical Engineering, 2015.

[15] P. Ravibabu, K. Venkatesh, and C. Kumar, "Implementation of Genetic Algorithm for Optimal Network Reconfiguration in Distribution Systems for Load Balancing”, In: Proc. of IEEE Region 8 International Conference on Computational Technologies in Electrical and Electronics Engineering, Vol. 10, No. 39, pp. 124-128, 2008.

[16] K. Nara, A. Shiose, M. Kitagawa and T. Ishihara, "Impl Ementation of Genetic Algorithm for Distribution Systems Loss Minimum Reconfiguration", Transactions on Power Systems, Vol. 7, No. 3, pp. 1044 - 1051, 1992.

[17] P. Ravibabu, M. Ramya, R. Sandeep, M. Karthik, and S. Harsha, "Implementation of Improved Genetic Algorithm in Distribution System with Feeder Reconfiguration to Minimize Real Power Losses", In: Proc. of IEEE 2nd International Conference on Computer Engineering and Technology, Vol. 4, No. 1, pp. 320-323, 2010.

[18] J. Singh and R. Bala, "A Case Study: Comparison of Newton-Raphson and GaussSeidal Load Flow Solution Techniques in Distributed Transmission and Generation Electricity Networks", International Journal of Advance Electrical and Electronics Engineering, Vol. 5, No. 1, pp. 17-25, 2016.

[19] H. Saadat and Tata Mc Grawhill, edition 2002.

[20] "On Load Flow Studies by Gauss-Seidel Method",

/https://www.ukessays.com/essays/engineering 18th May 2020 in Engineering.

[21] S. Bhuyan, S, Hazarika, and A. Bardalai, "Power Flow Analysis on IEEE 57 Bus System Using Mathlab", International Journal of Engineering 
Research \& Technology, Vol. 3, No. 8, pp. 11621171, 2014.

[22] J. Wiley, Electrical Power Systems, New Delhi, Indian, 1991.

[23] D. Kothari and I. Nagrath, Modern Power System Analysis, 4th edition, McGraw Hill, 2011.

[24] F. Ame and A. Idoko, "Load Flow Analysis Using Newton Raphson Method - A Case Study of South-West Nigeria $330 \mathrm{kV}$ Network", Ikule, IJARIIE, Vol. 5, Issue-3,2019.

[25] C. Yammani, S. Maheswarapu, and S. Matam, "Optimal Placement of Multi DGs in Distribution System with Considering the DG Bus Available Limits", Energy and Power, Vol. 3, No. 1, pp. 18-23, 2012.

[26] D. Goldberg, Genetic algorithms in search, optimization, and machine learning, India: Pearson Education, Inc., 2011.

[27] L. Luis, A. Luis, and H. Martins, "Reliability based design optimization using a genetic algorithm: application to bonded thin films areas of copper/polypropylene", Ingeniare. Revista chilena de ingeniería, Vol. 24, No. 3, pp. 510519, 2016.

[28] M. Baran, "Network Reconfiguration in Distribution Systems for Loss Reduction and Load Balancing", IEEE Transactions on Power Delivery, Vol. 4, No. 2, PP. 1401-1407, 1989.

[29] M. Hormozi, M. Jahromi, G. Nasiri, "Optimal Network Reconfiguration and Distributed Generation Placement in Distribution System Using a Hybrid Algorithm", International Journal of Energy and Power Engineering, Vol. 5, No. 5, pp. 163-170, 2016.

[30] S. Taher, and M. Karimi, "Optimal reconfiguration and DG allocation in balanced and unbalanced distribution systems", Ain Shams University, Ain Shams Engineering, ELSVER, Science Direct, Vol. 5, No. 3, pp. 735749, 2014.

[31] R. Rao, K. Ravindra, K. Satish, and S. Narasimham, "Power Loss Minimization in Distribution System Using Network Reconfiguration in the Presence of Distributed Generation", IEEE Transactions on Power System, Vol. 28, No. 1, pp. 317-325, 2013. 